九州大学学術情報リポジトリ

Kyushu University Institutional Repository

\title{
Pollen Tube Growth and Embryo Development in Interspecific Crosses of Cucurbita
}

Kwack, Soo Nyeon

University Farm, Faculty of Agriculture, Kyushu University

Fujieda, Kunimitsu

University Farm, Faculty of Agriculture, Kyushu University

https://doi.org/10.5109/23809

出版情報: 九州大学大学院農学研究院紀要. 30 (1)，pp.1-8，1985-09. Kyushu University バージョン：

権利関係 : 
J. Fac. Agr., Kyushu Univ., 30 (1), 1-8 (1985)

\title{
Pollen Tube Growth and Embryo Development in Interspecific Crosses of Cucurbita
}

\author{
Soo Nyeon Kwack and Kunimitsu Fujieda \\ University Farm, Faculty of Agriculture, Kyushu University 46-06, \\ Kasuyamachi, Fukuoka 811-23
}

(Received March 15, 1985)

\begin{abstract}
Pollen tube growth and seed production were investigated in a diallel involving three cultivated species (Cucurbita moschata, C. maxima, C. pepo) and a PM line selected from a cross between C. pepo x C. moschata in order to study the relationship between pollen tube growth and cross compatibility. All species combinations produced seeds with an embryo except one combination, C. pepo x C. maxima. The PM line, 'PM 143' showed similar results to C. moschata cv. 'Seoul-Dadagi' in pollen tube growth, fruit set and seed production in interspecific crosses. There were reciprocal differences in pollen tube growth, fruit set and seed production in $\mathrm{C}$. moschata $\times \mathbf{C}$. maxima, $\mathbf{P M} \times \mathbf{C}$. maxima and $\mathrm{C}$. maxima $\times \mathrm{C}$. pepo. The differences in seed production between reciprocal crosses seem a result of the differences in pollen tube growth and in embryo development after fertilization.
\end{abstract}

\section{INTRODUCTION}

Interspecific hybridization in Cucurbita has been studied in order to transfer promising characters from one species to other species and to determine taxonomic relationships among taxa. Whitaker and Davis (1962) summarized studies on interspecific crosses in the genus Cucurbita. A later striking work was the breeding of $P M$ lines, which have the early maturity and high female/male flower ratio of C. pepo cv. 'Zucchini' and the good flesh quality of C. moschata cv. 'Seoul-Dadagi' (Kim and Seo, 1976). Non-cultivated species have been crossed to cultivated species in order to exploit their disease resistance and to study evolution in this genus (Whitaker and Bemis, 1964; De Vaulx and Pitrat, 1980; Washek and Munger, 1983). Many workers have studied interspecific relationships by assessing fruit and seed set, and fertility of hybrid offspring (Whitaker and Davis, 1962). However, only a few reports focus on pollen tube growth in interspecific crosses (Hayase, 1950). Several techniques have been shown to aid in expediting interspecific crosses in Cucurbita, i.e. the use of highly heterozygous parents (Wall and York, 1962), bridging crosses (Rhodes, 1959), and embryo culture (Wall, 1954).

In this study, in vivo pollen tube growth and seed production were investigated in a diallel involving a $P M$ line and three cultivated species (C. moschata, C. maxima and C. pepo) in order to study the relationship between pollen tube growth and cross compatibility. 


\section{MATERIALS AND METHODS}

These experiments were carried out at the University Farm, Faculty of Agriculture, Kyushu University in 1984. We used C. moschata cv. 'Seoul-Dadagi', C. maxima cvs. 'Kuri' and 'Ebisu', C. pepo cvs. 'Zucchini' and 'Ford Zucchini' and a PM line, 'PM 143', selected from C. pepo cv. 'Zucchini' x C. moschata cv. 'Seoul-Dadagi', which resembles C. moschata in most characteristics. All of these cultivars are highly inbred lines. They were sown on March 20 and transplanted to the field on April 25. For each combination ten to twelve flowers were pollinated. About 50 days after pollination, fruits were harvested and after-ripened. Obtained seeds were sorted into empty seed, seed with a partially developed embryo and seed with a fully developed embryo.

For examining pollen tube growth, the same materials were sown directly in the field on August 24. To compare pollen tube growth in a self with that in an interspecific cross, we used 'Zucchini' selfs and 'Zucchini' $x$ 'Kuri'. The pollinated pistils were harvested at 1, 3, 6, 10, 15, 21, 36, 72, and 96 hours after pollination. In the diallel crosses, more than six flowers were pollinated for each cross, and the pistils were harvested three days after pollination. The lengths of the style above the ovary, the ovary, and the stylar canal in the ovary of selfs were measured. Pollen tube growth was examined by fluorescence microscopy using Kho and Baer's method (1968). We observed pollen tube growth at six cross sections of each flower, i.e. the middle part of the style above the ovary, the point where the style enters the ovary, and $1 / 4$, $2 / 4,3 / 4$, and $4 / 4$ the depth of the stylar canal in the ovary. The number of pollen tubes which had penetrated to each depth were counted.

\section{RESULTS}

Percent fruit set in intra- and inter-specific crosses among a PM line and three cultivated species of Cucurbita are presented in Table 1. Fruit set in all intraspecific crosses was at least $80 \%$. Interspecific crosses showed 0 to $100 \%$ fruit set, with only one combination, 'Zucchini' x 'Ebisu', producing no fruit. Percent fruit set of the PM line in interspecific crosses was in most cases similar to that of C. moschata cv. 'Seoul-Dadagi'. When used as the female par.

Table I. Percent fruit set in intra- and inter- specific crosses of Cucurbita

\begin{tabular}{|c|c|c|c|c|c|c|}
\hline \multirow{2}{*}{ q } & $P M^{*}$ & \multirow{2}{*}{$\begin{array}{c}\text { C. moschata } \\
\text { Seoul-Dadagi }\end{array}$} & \multicolumn{2}{|c|}{ C. maxima } & \multicolumn{2}{|c|}{ C. pepo } \\
\hline & PM 143 & & Kuri & Ebisu & Zucchini Ford & Zucchini \\
\hline PM 143 & $\ldots$ & 90.9 & 83.3 & 33.3 & 10.0 & 75.0 \\
\hline Seoul-Dadagi & 100 & - & 75. 0 & 50.0 & 70.0 & 100 \\
\hline Kuri & 33.3 & 33.3 & - & 85.7 & 10.0 & 58.3 \\
\hline Ebisu & 100 & 100 & 80.0 & & 58.3 & 50.0 \\
\hline Zucchini & 75.0 & 8.3 & 16.7 & 0 & & 100 \\
\hline Ford Zucchini & 100 & 83.3 & 100 & 100 & 100 & - \\
\hline
\end{tabular}

* A line selected from C. pepo x C. moschata. 
ent, C. pepo cv. 'Ford Zucchini' showed a higher percent fruit set than the other cultivars. When used as the pollen parent, C. pepo cv. 'Zucchini' had lower ability to set fruit than any other cultivar.

Table 2 presents seed production per pollinated flower on the basis of embryo development. Embryo development in the cross between the $\mathbf{P} \mathbf{M}$ line, 'PM 143', and C. moschata cv. 'Seoul-Dadagi' was similar to that in intraspecific crosses of C. maxima and C. pepo. Seeds with a fully developed embryo were obtained in crosses between PM, C. moschata and C. maxima, and another cross, 'Zucchini' x 'PM 143'. C. maxima x C. moschata and C. maxima x PM produced about ten seeds with a fully developed embryo per pollinated flower. In their reciprocal crosses, 'Ebisu' showed lower ability to produce seeds with a fully developed embryo than 'Kuri'. PM $\times$ C. pepo and C. moschata $\mathbf{x}$ C. pepo produced a few seeds with a partially developed embryo reciprocally. Unilateral incompatibility was found in the cross between $\mathrm{C}$. maxima and C. pepo. C. maxima x C. pepo produced 1.5-8.5 seeds with a partially developed embryo, but its reciprocal cross produced no seeds with an embryo.

The lengths of the style above the ovary, the ovary, and the stylar canal

Table 2. Seed production per pollinated flower in intra- and inter- specific crosses of Cucurbita

\begin{tabular}{|c|c|c|c|c|c|c|c|c|}
\hline \multirow{2}{*}{ 우 } & \multirow{2}{*}{ 令 } & P M & \multirow{2}{*}{$\begin{array}{l}\text { C. moschata } \\
\text { Seoul-Dadagi }\end{array}$} & \multicolumn{2}{|c|}{ C. maxima } & \multicolumn{3}{|c|}{ C. pepo } \\
\hline & & PM 143 & & Kuri & Ebisu & Zucchini & Ford & Zucchini \\
\hline \multirow{3}{*}{ PM 143} & A* & - & 0 & 13.5 & 0.8 & 1.0 & & 19.3 \\
\hline & B & - & 2. 5 & 2.9 & 2.9 & 0.1 & & 3.8 \\
\hline & $\mathrm{C}$ & & 224.2 & 9.2 & 0 & 0 & & 0 \\
\hline \multirow{3}{*}{ Seoul-Dadagi } & A & 0 & $\ldots$ & 15.4 & 2.3 & 14. 6 & & 44.0 \\
\hline & B & 1.1 & & 3.7 & 1.9 & 2.3 & & 8.0 \\
\hline & $\mathrm{C}$ & 198.5 & 一 & 9.4 & 0.8 & 0 & & 0 \\
\hline \multirow{3}{*}{ Kuri } & A & 13.8 & 8.3 & & 0 & 5.6 & & 21.3 \\
\hline & B & 8.8 & 3.7 & & 4. 1 & 1.5 & & 1.9 \\
\hline & $\mathrm{C}$ & 7.5 & 11.4 & $\rightarrow$ & 140.3 & 0 & & 0 \\
\hline \multirow{3}{*}{ Ebisu } & A & 8.3 & 4. 0 & 0 & - & 22.1 & & 17.9 \\
\hline & B & 34.6 & 52.4 & 8.9 & - & 8. 5 & & 1.6 \\
\hline & $\mathrm{C}$ & 11.5 & 15.7 & 74.1 & - & 0 & & 0 \\
\hline \multirow{3}{*}{ Zucchini } & A & 1.3 & 4. 4 & 2. 9 & 0 & - & & 0 \\
\hline & B & 3.9 & 1.9 & 0 & 0 & & & 2.4 \\
\hline & C & 1.4 & 0 & 0 & 0 & - & & 98.0 \\
\hline \multirow{3}{*}{ Ford Zucchini } & A & 7. 7 & 5. 1 & 14.9 & 13. 1 & 0 & & - \\
\hline & B & 4.6 & 1.9 & 0 & 0 & 3.3 & & - \\
\hline & $\mathrm{C}$ & 0 & 0 & 0 & 0 & 117.6 & & \\
\hline
\end{tabular}

* A, empty seed; B, seed with a partially developed embryo; C, seed with a fully developed embryo. 
in the ovary of selfs measured at three days after pollination are presented in Table 3. The range in length of the style above the ovary was 2.0-3.2 $\mathrm{cm}$. Total stylar canal length was very different among cultivars. The longest total stylar canal was $12.1 \mathrm{~cm}$ in a pistil of 'PM 143 ', and the shortest was $4.1 \mathrm{~cm}$ in a pistil of 'Ebisu'.

Table 3. Lengths of style above the ovary, ovary, and stylar canal in the ovary of selfs measured three days after pollination

\begin{tabular}{|c|c|c|c|c|}
\hline Cultivar & $\begin{array}{c}\text { Style above } \\
\text { the ovary } \\
(\mathrm{cm})\end{array}$ & $\begin{array}{r}\text { Ovary } \\
(\mathrm{cm})\end{array}$ & $\begin{array}{l}\text { Stylar canal } \\
\text { in the ovary } \\
(\mathrm{cm})\end{array}$ & $\begin{array}{c}\text { Total stylar } \\
\text { canal } \\
(\mathrm{cm})\end{array}$ \\
\hline PM 143 & 3. oio. 2 & $11.6 \pm 1.5$ & $9.1 \pm 1.2$ & 12. Ifl. 4 \\
\hline Seoul-Dadagi & $3.2 \pm 0.1$ & $11.2 \pm 0.6$ & $7.8 \pm 0.7$ & $11.0 \pm 0.3$ \\
\hline Kuri & $2.5 \pm 0.1$ & $4.0 \pm 0.5$ & 2. $1 \mathrm{f} 0.3$ & $4.6 \pm 0.4$ \\
\hline Ebisu & $2.2 \pm 0.2$ & $3.9 \pm 0.4$ & $1.9 \pm 0.1$ & $4.1 \pm 0.5$ \\
\hline Zucchini & 2. $4 \pm 0.1$ & $12.6 \pm 2.2$ & $9.2 \pm 1.5$ & $11.6 \pm 1.4$ \\
\hline Ford Zucchini & 2 , oio, 1 & $10.3 \pm 1.0$ & $6.9 \pm 0.6$ & $8.9 \pm 0.7$ \\
\hline
\end{tabular}

Fig. 1 depicts the pollen tubes at cross sections of a pistil. With the aid of the fluorescence technique the pollen tubes in the stylar canal were clearly discernible,

Fig. 2 shows pollen tube growth in 'Zucchini' selfs and 'Zucchini' $\mathbf{x}$ 'Kuri' observed at various hours after pollination. One hour after polliation, pollen had germinated on the stigma in both crosses. Six hours after pollination, pollen tubes of 'Zucchini' had penetrated into the stylar canal in the ovary of 'Zucchini', but those of 'Kuri' had not. By 72 hours after pollination, pollen tubes of 'Zucchini' selfs had grown into about $4 / 4$ the depth of the stylar canal in the ovary. However, pollen tubes of 'Kuri' had grown to about 1/4 the depth of the stylar canal in the ovary of 'Zucchini' and had been arrested there.

Pollen tube growth in intra- and inter-specific crosses is shown in Fig. 3. Selfs and intraspecific crosses resulted in good pollen tube growth. Pollen tube growth in the crosses between 'PM 143' and C. moschata cv. 'Seoul-Dadagi' was similar to that in intraspecific crosses. When C. maxima was used as the female parent, the interspecific crosses showed good pollen tube growth. In C. pepo, the interspecific crosses of 'Zucchini' showed poor pollen tube growth, but those of 'Ford Zucchini' showed good growth.

\section{DISCUSSION}

Reports on interspecific hybridization within the genus Cucurbita are rather extensive (Whitaker and Davis, 1962). But according to Whitaker and Davis' summary, interspecific hybrids can be obtained only with difficulty from most species combinations of the cultivated Cucurbita. Our results showed that all species crosses produced seeds with an embryo except C. pepo x C. maxima (Table 2). In our study, 'PM 143', selected from C. pepo cv. 'Zucchini' x C. moschata cv. 'Seoul-Dadagi', was crossed with three cultivated species to investi- 

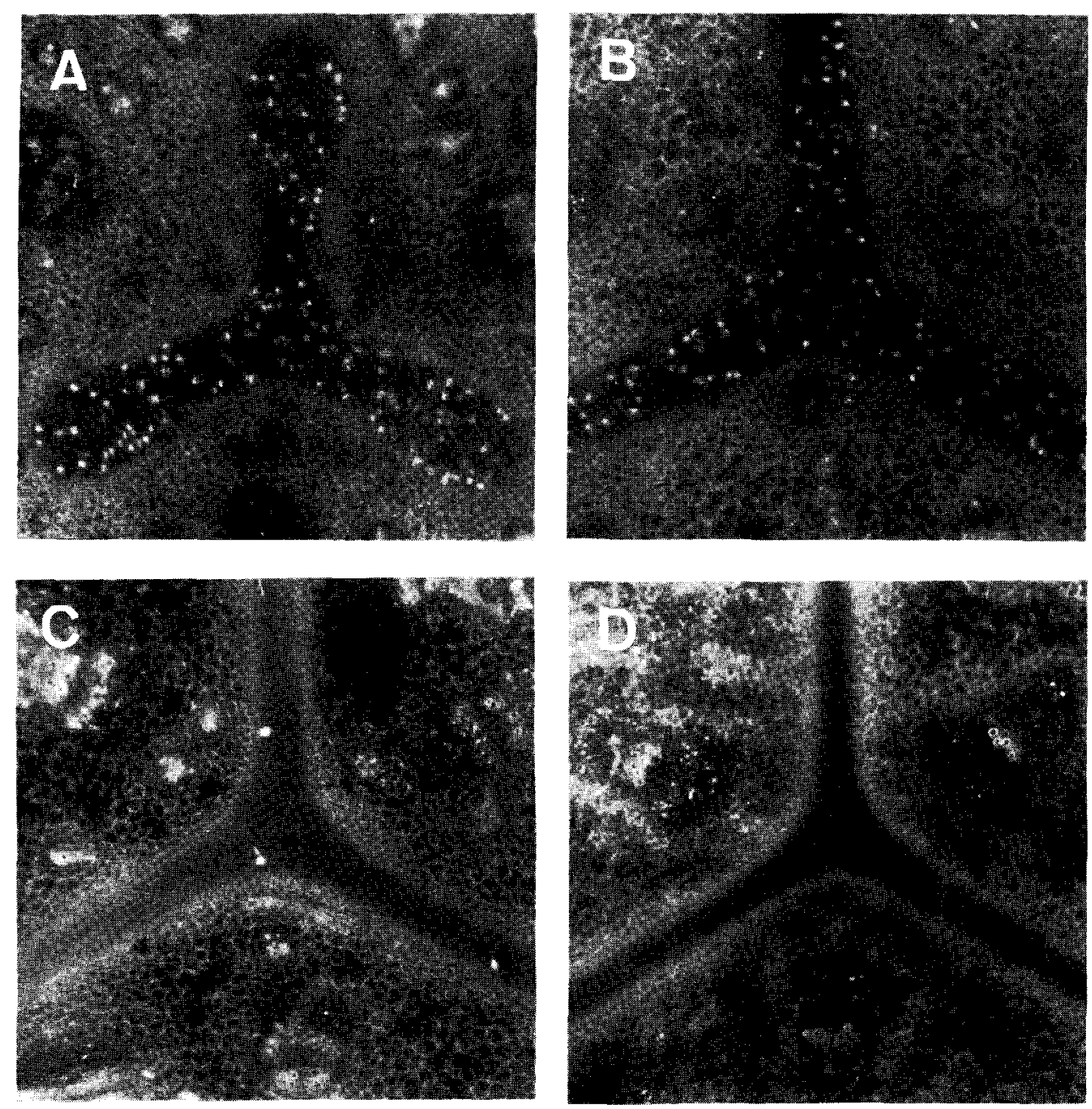

Fig. 1. Cross sections showing the penetration of pollen tubes into the stylar canal. A, many pollen tubes at the point where the style enters the ovary; $\mathrm{B}$, many pollen tubes in the stylar canal in the ovary; $\mathrm{C}$, three pollen tubes in the stylar canal in the ovary; $D$, no pollen tubes in the stylar canal in the ovary.

gate the possibilty of using 'PM 143' as a bridge plant. Although 'PM 143' has the cytoplasm of C. pepo, 'PM 143' x 'Seoul-Dadagi' reciprocally produced as many seeds as intraspecific crosses, and pollen tube growth and seed production in interspecific crosses of 'PM 143' showed similar results to those of 'Seoul-Dadagi'. These results indicate that the interaction between the cytoplasm and the nuclear genes does not play an important role in the success of interspecific crosses of Cucurbita. The differences between cultivars of C. maxima resulted in the great differences in seed production in $P M \times C$. maxima and $\mathrm{C}$. 


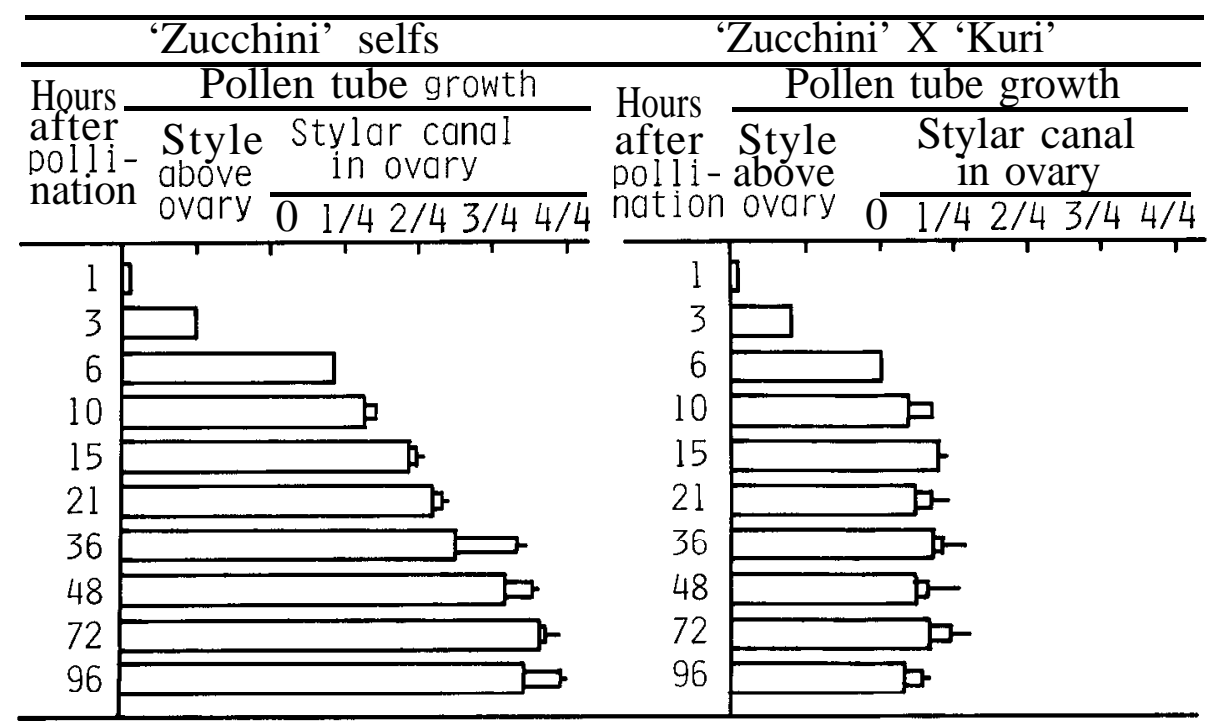

Fig. 2. Pollen tube growth in 'Zucchini' selfs and 'Zucchini' $\mathrm{x}$ 'Kuri' observed at various hours after pollination. [ $]$, more than 30 pollen tubes observed ; 口, 10-30 pollen tubes observed; ,1-9 pollen tubes observed.

moschata x C. maxima. Accordingly, the genetic constitution seems important in the success of interspecific crosses of Cucurbita.

Total stylar canal length was very different among cultivars (Table 3). C. maxima, with a short stylar canal, showed good pollen tube growth in the ovary of 'Ford Zucchini', with a long stylar canal (Fig. 3). So we suggest that the difference between the stylar canal length of the cultivars is not so important in interspecific crosses of Cucurbita.

Pollen tubes of C. maxima cv. 'Kuri', compared with those of 'Zucchini', grew slowly and were arrested at about $1 / 4$ the depth of the stylar canal in the ovary of C. pepo cv. 'Zucchini' (Fig. 2). These results were consistent with Hayase's findings (1950) that pollen tube growth in C. pepo x C. maxima is inhibited in the upper region of the ovaries. However, pollen tubes in other crosses, C. pepo cv. 'Ford Zucchini' x C. maxima cv. 'Kuri' or 'Ebisu', grew into $3 / 4$ the depth of the stylar canal in the ovary (Fig. 3). These differences may result from the difference in cultivars involved.

The observations on pollen tube growth in the stylar canal agreed with fruit set as a rule, but did not always agree with seed production. Although 'Ford Zucchini' x C. maxima showed good pollen tube penetration into the deep stylar canal in the ovary, they produced no seeds with an embryo. We observed many ovules penetrated by pollen tubes in these crosses. These results indicate that after fertilization the embryo may degenerate in the early developmental stage.

Reciprocal crosses showed great differences in pollen tube growth, fruit set and seed production in C. moschata x C. maxima, PM x C. maxima and C. max- 


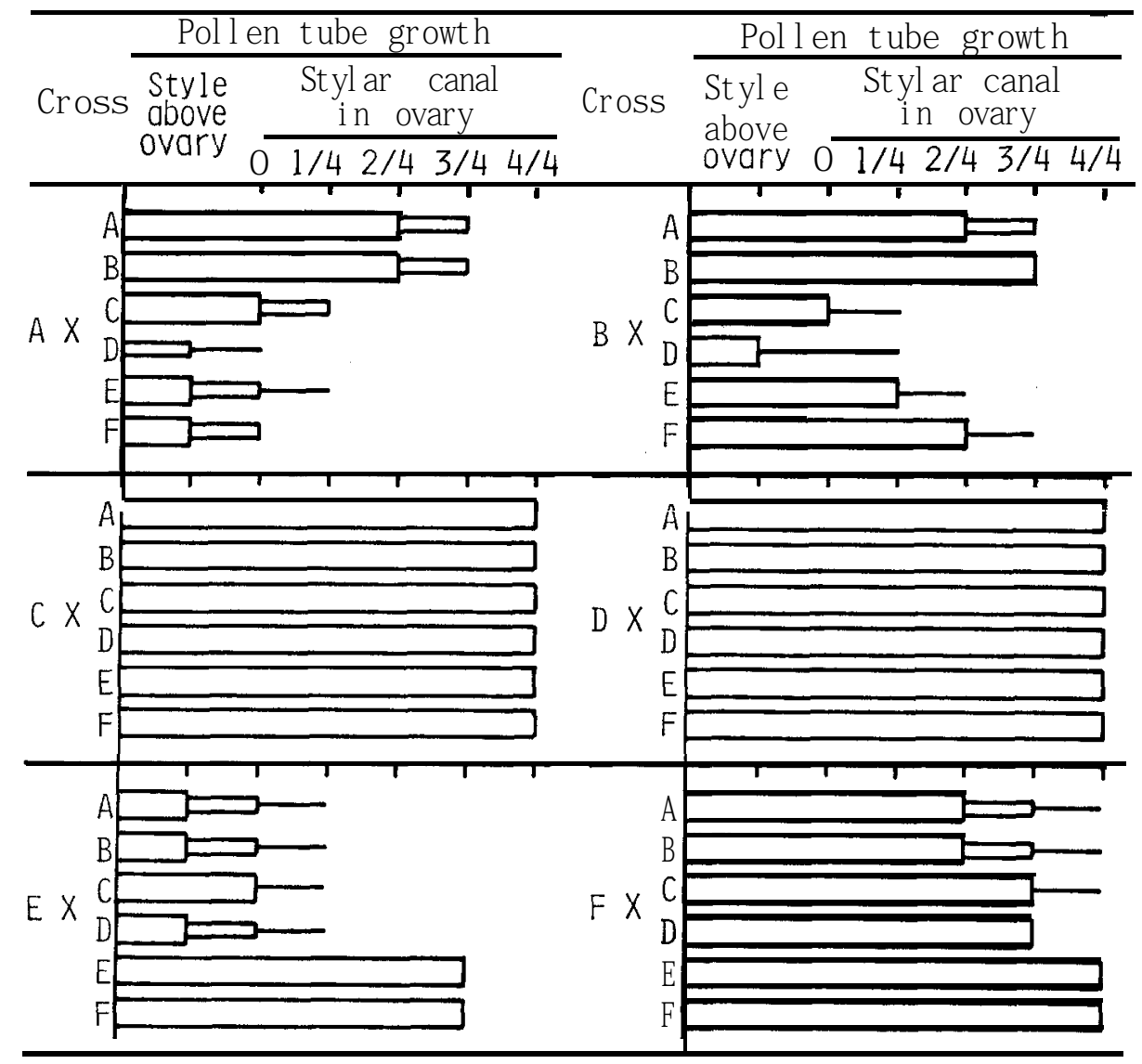

Fig. 3. Pollen tube growth in intra- and inter- specific crosses of Cucurbita. A, a PM line, 'PM 143'; B, C. moschata cv. 'Seoul-Dadagi'; C and D, C. maxima cvs. 'Kuri' and 'Ebisu'; E and F, C. pepo cvs. 'Zucchini' and 'Ford Zucchini'. $\square$, more than 30 pollen tubes observed; $\square, 10-30$ pollen tubes observed ; - 1-9 pollen tubes observed.

imax C. pepo. The differences in pollen tube' growth and embryo development may result in the differences in seed production between reciprocal crosses.

\section{ACKNOWLEDGEMENTS}

We wish to thank the Hungnong Seed Company, Seoul, Korea for providing seed materials and also Miss G. M. Caddell for help in preparing this manuscript.

\section{REFERENCES}

De Vaulx, R. D. and M. Pitrat 1980 Realization of the interspecific hybridization (F, 
and $\mathrm{BC}_{1}$ ) between Cucuybita pepo and $\mathrm{C}$. ecuadoyensis. Cucuybit Genetics Cooperative, $3: 42$ Hayase, H. 1950 Cucuybita-crosses, I. The pollen tube growth in interspecific crosses. Jap. Jour. Genet., 25: 181-190 (in Japanese with English Resume)

Kho, Y. and J. Baer 1968 Observing pollen tubes by means of fluorescence. Euphytica, 17: 298-302

Kim, B. H. and Y. G. Seo 1976 Studies on the interspecific crosses. (II) Breeding process and characteristics of Bulam Sacheol Aehobak. Jour. Kor. Soc. Hoyt. Sci., 17: 38-46 (in Korean with English abstract)

Rhodes, A. M. 1959 Species hybridization and interspecific gene transfer in the genus Cucuybita. Proc. Amer. Soc. Hort. Sci., 74: 546-551

Wall, J. R. 1954 Interspecfic hybrids of Cucuybita obtained by embryo culture. Proc. Amer. Soc. Hort. Sci., 63: 427-430

Wall, J. R. and T. L. York 1962 Gametic diversity as an aid to interspecific hybridization in Phaseolus and Cucuybita. Proc. Amey. Soc. Hor . Sci., 75: 419-428

Washek, R. L. and H. M. Munger 1983 Hybridization of Cucurbita pepo with disease resistant Cucuybita species. Cucurbit Genetics Cooperative. 6: 92

Whitaker, T. W. and W. P. Bemis 1964 Evolution in the genus Cucurbita. Evolution, 1 8: 553-559

Whitaker, T. W. and G. N. Davis 1962 Cucurbits, botany, cultivation and utilization. Leonard Hill Books Ltd., London (England) 